\title{
Análise da influência do tempo e da trajetória do olhar na probabilidade de ofuscamento em ambientes de escritório
}

\author{
Analysis of the influence of time and sight trajectories on \\ daylight glare probability in office environments
}

\section{Gabriela Silva Goedert \\ Natalia Giraldo Vasquez \\ Fernando Oscar Ruttkay Pereira}

\section{Resumo}

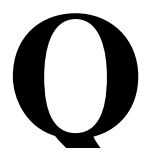

uantificar e caracterizar a percepção do brilho na atividade visual ainda é um desafio nas pesquisas, por se tratar de um parâmetro relativo à posição ativa do ocupante. $\mathrm{O}$ objetivo desta pesquisa foi considerar o usuário dinâmico em ambientes de trabalho, verificando a influência do tempo de visualização e da direção do olhar na redução da probabilidade de ofuscamento. Os dados foram levantados em um ambiente real com 26 participantes, monitorados enquanto realizaram atividades comuns em escritórios. As movimentações do olhar foram registradas usando óculos eyetracker. Através de imagens high dynamic range (HDR) foram mapeados os brilhos das superfícies e obtida a probabilidade de ofuscamento $(D G P)$. Esses dados foram correlacionados com as respostas de satisfação dos usuários, obtida por meio de questionários. Constatou-se que, ao realizar uma tarefa, o usuário mantém seu olhar fixo no plano de trabalho e, durante períodos de pausa, o olhar tornou-se mais disperso. As aberturas foram visualizadas, principalmente, quando localizadas no plano de fundo da tarefa ou quando suas luminâncias foram menores. Concluiu-se que os valores de $D G P_{\text {ponderado }}$ estiveram mais próximos dos votos de satisfação manifestados pelos participantes, ressaltando a importância de considerar as direções de visão e o tempo de visualização nesta avaliação.

Palavras-chave: Conforto visual. Tempo de visualização. Trajetória do olhar. Ofuscamento. Tarefa visual.

\footnotetext{
${ }^{1}$ Gabriela Silva Goedert ${ }^{1}$ Universidade Federal de Santa Catarina

Florianópolis - SC - Brasil
}

\section{Abstract}

To quantify and characterise the perception of brightness in visual activity is still a challenge for researchers, mainly because it is a subjective parameter, dependent on the active position of the occupant. The aim of thisstudywas to consider dynamic users in work environments and verify the influence of viewing time and sight direction on glare probability. The data were collected in a real environment where 26 volunteers were monitored while performing common office tasks. The gaze movements were recorded with an Eye-Tracker device. Through High Dynamic Range (HDR) images the surfaces' brightnesses were mapped and the glare probability index (DGP) was calculated. Those data were correlated with the users' satisfaction answers obtained through questionnaires. The researchers found that, when performing a task, users keep their eyes fixed on the task surface, and during break periods, the sight became more dispersed. The windows were mainly visualised when they were part of the task's background or when their luminance values were low. The conclusionwas that DGP $P_{\text {weighted }}$ values were closer to the satisfaction votes expressed by the participants, emphasising the importance of considering vision directions and viewing time in this analysis.

Keywords: Visual comfort. Viewing time. Sight trajectory. Glare. Visual task. 


\section{Introdução}

O conforto visual está relacionado ao dinamismo da luz natural. As principais causas de desconforto são geralmente relacionadas à incapacidade de o sistema visual se adaptar às condições dinâmicas e direcionais do brilho dos componentes da cena, podendo gerar diferentes padrões comportamentais (WIENOLD; CHRISTOFFERSEN, 2006), os quais são difíceis de ser definidos. As reações do sistema visual às condições de iluminação têm sido alvo de estudos que propõem modelos para a inclusão das sensações visuais nos índices usados na avaliação do ofuscamento (CHOI; ZHU, 2015; HAMEDANI et al., 2019, 2020; HOWARTH et al., 1993; STONE, 2009; SWEITZER; SAITO, 1995; YAMIN GARRETÓN et al., 2015). Em um estudo inicial, Howarth et al. (1993) não encontraram relação entre a variação no tamanho da pupila e a sensação de desconforto; porém, estudos posteriores afirmaram que a dita variação é sim um indicador de conforto visual (CHOI; ZHU, 2015; SWEITZER; SAITO, 1995). A percentagem de abertura dos olhos foi o indicador usado por Yamin Garretón et al. (2015) para avaliar o ofuscamento causado pela radiação direta. Segundo os autores, esses dados complementam as respostas subjetivas dos participantes, assim como os dados obtidos através do cálculo do ofuscamento (YAMIN GARRETÓN et al., 2015). Choi e Zhu (2015) identificaram que a resposta visual e as sensações visuais poderiam ser avaliadas a partir das mudanças no tamanho da pupila, devido a que o sistema visual responde de forma automática aos estímulos do ambiente, já que é controlado pelo sistema nervoso parassimpático (CHOI; ZHU, 2015). Recentemente, Hamedani et al. (2020) concluíram que, sob condições de maior desconforto visual as respostas das medidas fisiológicas testadas (fixação visual, piscadas e diâmetro da pupila) foram significativamente diferentes às respostas visuais sob condições menos desconfortáveis.

Além dos aspectos fisiológicos, a avaliação da sensação causada pelo brilho envolve parâmetros subjetivos e relativos ao carácter dinâmico dos usuários dos ambientes. Estudos sobre o tema geralmente englobam ocupantes estáticos (WIENOLD, 2009), na contramão do dinamismo das pessoas e da visão em situações reais. Devido às múltiplas variáveis que envolvem a avaliação de conforto visual, as técnicas e os equipamentos usados nos estudos experimentais também são diversos (VIEIRA DIAS et al., 2017; YACINE et al., 2017). Esses estudos são fonte de valiosas informações referentes ao comportamento dos usuários as quais, ao não poderem ser obtidas através de simulações computacionais, lhes atribuem grande valor.

O dinamismo dos usuários tem sido incorporado em alguns estudos que incluem novos parâmetros e métodos de medição e geram modelos comportamentais com relação a como o ambiente é realmente experimentado visualmente. Nesses estudos, a direção de visão é composta pela movimentação do corpo, da cabeça e dos olhos do usuário. Jakubiec e Reinhart (2012) propuseram o modelo de zonas adaptativas, o que permitiu, através de simulação, a variação na direção de visão do observador para evitar o desconforto causado pelo brilho. Ao aplicar esse conceito foi significantemente ampliada a precisão em predizer o conforto dos ocupantes. Sarey Khanie et al. (2011, 2013a, 2013b, 2015, 2016) integraram na análise do brilho, em levantamentos em campo, o rastreamento da visão (eye-tracking) e o mapeamento das luminâncias do campo visual usando imagens de ampla faixa dinâmica (high dynamic range - HDR), técnica validada e difundida nos últimos anos em estudos em ambientes reais (INANICI, 2006). Os resultados considerando o dinamismo da visão foram comparados com resultados obtidos com o olhar dos usuários fixo na área de tarefa e quando esteve em direção à janela. Os resultados demonstraram que há uma diferença significativa na avaliação do ofuscamento ao considerar essa mudança de direção do olhar. Giraldo Vasquez et al. (2016) também apresentaram um procedimento para inclusão do tempo e direção do olhar. Nesse estudo os resultados indicaram uma redução de até $30 \%$ no daylightglare index (DGI) total de um ambiente de sala de aula com relação ao DGI estático, caso fosse considerado o tempo de permanência do olhar em cada direção.

Outras pesquisas abordam a questão do conteúdo da cena que está sendo observada, do contato visual com o exterior e das tarefas que estão sendo realizadas (ALTOMONTE et al., 2016). Sarey Khanie et al. (2016) constataram que nos intervalos das tarefas os usuários olharam para a janela do ambiente. Em relação à paisagem vista pela janela, Tuaycharoen e Tregenza $(2005,2007)$ concluíram que, ao comparar cenas visuais com a mesma luminância, quando os usuários estiveram interessados na cena visual a sensação de ofuscamento foi menor do que quando olharam para uma cena visual que consideraram menos interessante.

Mesmo que em todas as pesquisas acima mencionadas os autores buscaram incorporar o dinamismo dos usuários na avaliação do ofuscamento, as variáveis que influenciam na percepção visual e sensação de conforto foram estudadas de forma independente. Essa abordagem dificulta a comparação da relação direta da mudança de comportamento do usuário com relação ao ambiente luminoso disponível, com as tarefas realizadas e com as vistas externas. Considerar essas interdependências entre os diferentes parâmetros 
avaliados pode significar mudanças na tolerância dos usuários com relação ao brilho. Diante dos avanços alcançados nas pesquisas mais recentes, este trabalho busca contribuir para a evolução do aperfeiçoamento dos índices utilizados na avaliação da sensação de ofuscamento, ao considerar o usuário dinâmico em ambientes de trabalho, verificando a influência que teria o tempo de visualização e da direção do olhar no cálculo da probabilidade de ofuscamento.

\section{Método}

O levantamento dos dados foi realizado através de estudos de campo em um ambiente real de escritório durante fevereiro e março de 2017. As técnicas e os instrumentos usados no levantamento de dados envolveram: rastreamento da visão dos participantes por meio de óculos eye-tracker, mapeamento de luminâncias por meio de fotografias $H D R$ e avaliação subjetiva dos participantes levantada através de um questionário. Os dados foram tabulados e tratados estatisticamente conforme as características das variáveis analisadas.

\section{Características do ambiente de escritório e dos participantes}

Os levantamentos ocorreram em uma sala de estudos localizada na Universidade Federal de Santa Catarina, Florianópolis (Latitude: $27^{\circ} \mathrm{S}$, Longitude $48^{\circ} \mathrm{W}$ ). Dentro do ambiente foram escolhidas quatro posições (P01, P02, P03 e P04) para a localização dos participantes, a partir das quais a área das aberturas no campo visual e a relação com a iluminação variou (Figura 1). A sala possui duas janelas: a janela J01 com 5,93 $\mathrm{m}^{2}(2,30 \mathrm{~m}$ de largura x 2,58 m de altura) e a janela J02 com 2,2 $\mathrm{m}^{2}$ (1,07 m de largura x 2,05 m de altura). A posição das persianas permaneceu conforme a configuração usada pelos usuários do ambiente (entreabertas) e as lâmpadas foram ligadas apenas após as $17 \mathrm{~h}$. O sistema de iluminação artificial é composto por quatro luminárias de sobrepor com aletas reflexivas, cada uma com 2 lâmpadas fluorescentes T8.

Os dados foram levantados com a participação de 26 voluntários com média de idade de 27 anos, sendo 14 homens e 12 mulheres. Ressalta-se que 10 participantes eram usuários frequentes do ambiente monitorado.

\section{Trajetória da visão usando eye-tracker}

Na chegada cada participante foi localizado em um dos pontos de avaliação e foi realizada a calibração dos óculos eye-tracking. Foram definidas atividades típicas de escritório na seguinte ordem: leitura e escrita no monitor, leitura e escrita no papel e falar ao telefone. A trajetória da visão foi obtida com os óculos eye gaze tracker da Senso Motoric Instruments. Os dados foram arquivados em forma de vídeos usando o programa Iview ETG 2.6, os quais permitiram a obtenção de informações: temporais, de foco e da trajetória do olhar de cada participante. Cada tarefa realizada foi dividida em três fases (entrada, pensamento e interação); e o monitor foi desligado em determinados momentos (Tabela 1).

Os dados obtidos com os óculos eye-tracker foram diferenciados em função dos processos visuais (fixações e sacadas), distinguindo e definindo o foco e a permanência do olhar em determinada superfície. A análise dos dados foi realizada no programa $B e$ Gaze 3.6, que possibilita a criação de diferentes mapas, tais como: caminho traçado pelo olho, manchas de pontos focais e gráficos de áreas de interesse pré-definidas. Dessa forma foi possível identificar para cada participante para quais direções a visão foi mais frequentemente dirigida, sobre quais superfícies esteve mais focada a visão e quais as principais áreas de interesse visual.

Para cada participante, e a partir de uma imagem de referência do campo visual central, foi realizada a sobreposição da trajetória do olhar. Na mesma imagem foram demarcadas as seguintes áreas de interesse: tela do monitor (plano vertical), teclado, folha de papel, bancada de trabalho (plano horizontal), plano de fundo, aberturas, paredes laterais e teto (Figura 2a). Posteriormente, foram demarcadas na mesma imagem as áreas de interesse por direção: esquerda, central e direita (Figura 2b). A demarcação das áreas de interesse permitiu obter dados de recorrências visuais, caracterizar o percurso da visão e identificação das direções de visão dominantes de cada participante durante cada tarefa, bem como extrair o tempo de visualização.

\section{Mapeamento das luminâncias no campo visual}

O mapeamento das luminâncias do campo visual de cada participante foi realizado através de imagens $H D R$, em três direções da visão (direita, central e esquerda), definidas com um ângulo de $60^{\circ}$ a partir da região central. Para cada direção da visão foi levantada a sequência de imagens lowdinamic range (LDRi) usada para o cálculo da imagem HDR. Para isso foi utilizada uma câmera Canon_EOS60D com lente olho de peixe 
(EX Sigma - Circular Fisheye $4.5 \mathrm{~mm} 1$ - 2.8), controlada de forma remota. As configurações usadas para os levantamentos das LDRi são apresentadas na Tabela 2. Para os participantes de cada posição dentro do ambiente, esses levantamentos foram realizados no tempo de troca dos participantes: imediatamente após o monitoramento da direção da visão de um participante e antes de iniciar o monitoramento da direção da visão do seguinte. No total foram calculadas 48 imagens $H D R$.

O cálculo dos mapas de luminância e o índice daylight glare probability $(D G P)$ foram realizados no programa Aftab Alpha v.2.1 (MIRI; ASHTARI, 2015), interface gráfica do Evalglare. Foi considerada a sensação de ofuscamento como: imperceptível quando o valor de DGP foi menor que 0,30; perceptível quando o valor de $D G P$ variou entre 0,30 e 0,35 ; perturbador quando o valor de $D G P$ variou entre 0,35 e 0,40 e intolerável quando os valores de $D G P$ foram maiores que 0,45 .

\section{Figura 1 - Características do ambiente e as posições analisadas com seus campos visuais}

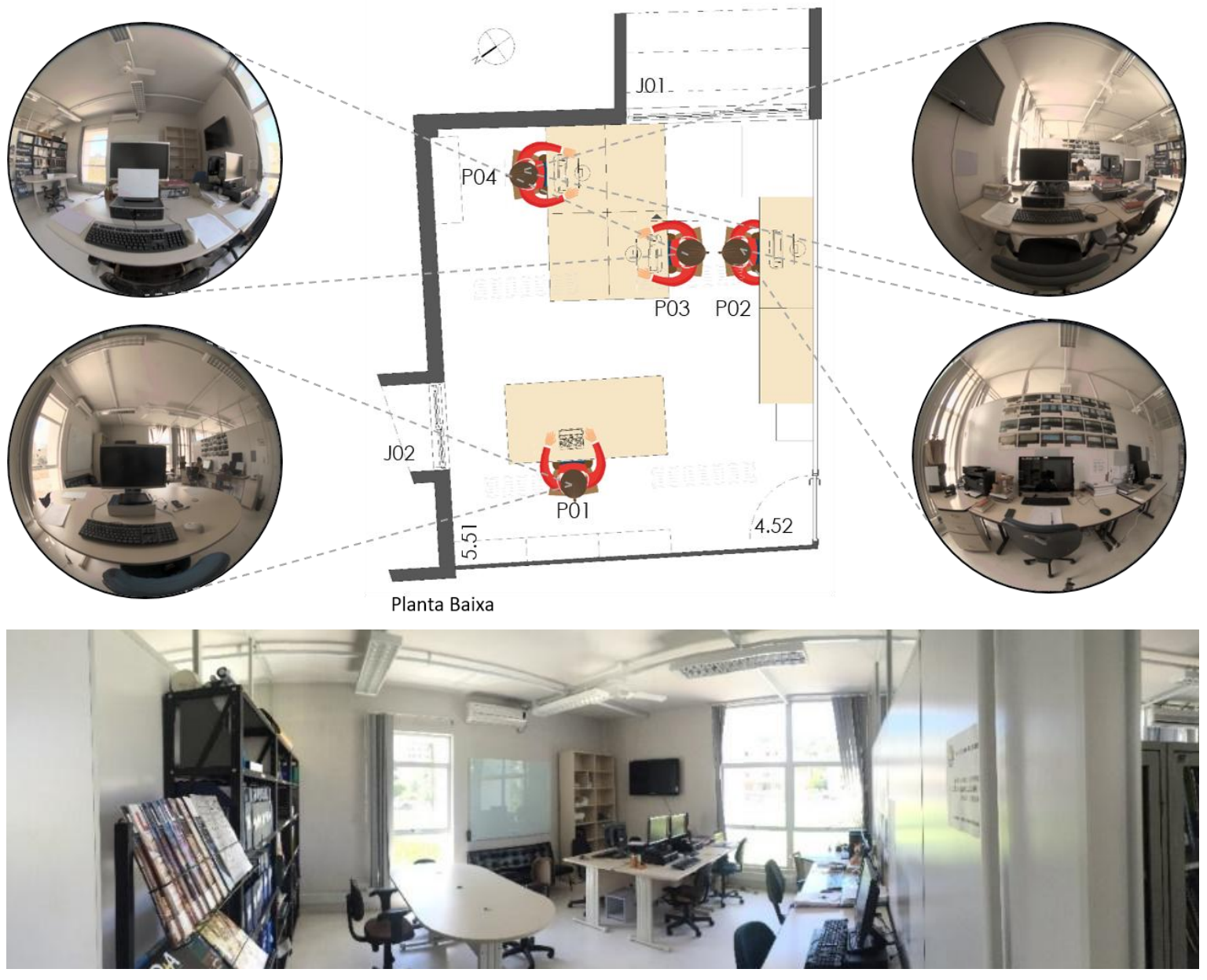

Tabela 1 - Sequência das tarefas

\begin{tabular}{l|l|l|l|l}
\hline \multirow{2}{*}{ Tarefas } & Plano de & \multicolumn{3}{c}{ Fases } \\
\cline { 3 - 5 } & trabalho & \multicolumn{1}{|c}{ Entrada } & \multicolumn{1}{c}{ Pensamento } & Interação \\
\hline $\begin{array}{l}\text { Leitura e } \\
\text { escrita }\end{array}$ & $\begin{array}{l}\text { Vertical - } \\
\text { Monitor }\end{array}$ & $\begin{array}{l}\text { Ler o texto e a } \\
\text { pergunta }\end{array}$ & $\begin{array}{l}\text { Desligar o monitor e } \\
\text { refletir sobre o tema }\end{array}$ & Digitar a resposta \\
\hline Desligamento do monitor & $\begin{array}{l}\text { Horizontal } \\
\begin{array}{l}\text { Leitura e } \\
\text { escrita }\end{array}\end{array}$ & $\begin{array}{l}\text { Ler o texto e a } \\
\text { pergunta }\end{array}$ & Refletir sobre o tema & Escrever a resposta \\
\hline $\begin{array}{l}\text { Falar ao } \\
\text { telefone }\end{array}$ & - & $\begin{array}{l}\text { Atender o } \\
\text { telefone }\end{array}$ & Escutar o locutor & Falar com o locutor \\
\hline
\end{tabular}


Figura 2 - (a) Divisão das áreas de interesse no campo visual na P03 e (b) Divisão das três direções de interesse no campo visual na P03

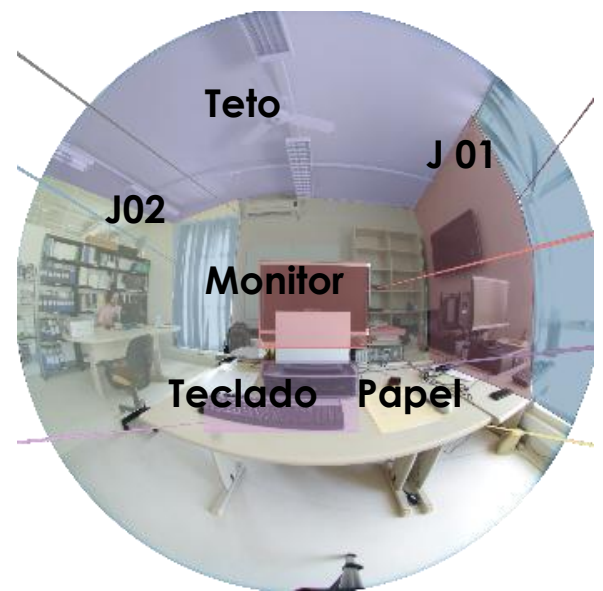

(a)

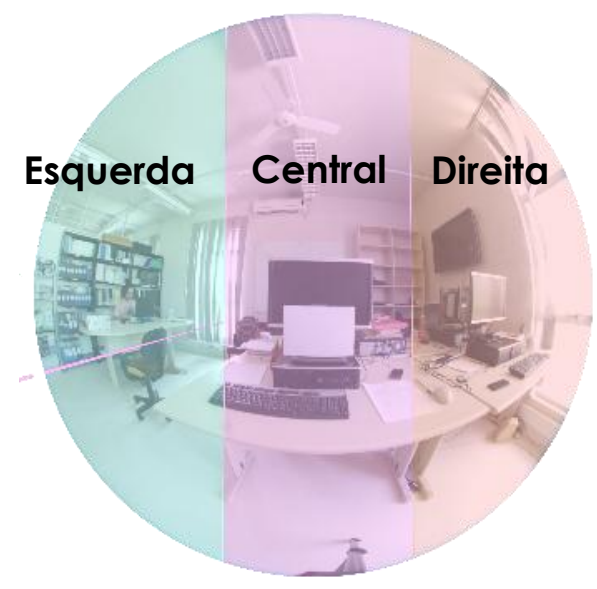

(b)

Tabela 2 - Configurações da câmera

\begin{tabular}{c|c|c|c}
\hline Característica & Configuração & Característica & Configuração \\
\hline Balanço branco & Luz natural & Tamanho imagem & $3.456 \times 2.304$ pixels \\
Foco & Automático & Sensibilidade & ISO100 \\
f-stop & f/11 & Lentes & Fisheye \\
Shutter speed & Variável & Formato & RAW e JPG \\
\hline
\end{tabular}

\section{Impacto do tempo de visualização na sensação de ofuscamento}

Visando introduzir o caráter dinâmico da visão dos participantes foi realizada a ponderação dos valores de $D G P$ de cada direção da visão pelo tempo de permanência do olhar em cada uma delas (Equação 1) (GIRALDO VASQUEZ et al., 2016), para dessa forma obter o valor do DGP ponderado (DGP $)$ de cada participante.

$D G P_{p}=\left(D G P_{d v E} * \% t_{d v E}\right)+\left(D G P_{d v C} * \% t_{d v \mathrm{C}}\right)+\left(D G P_{d v D} * \% t_{d v D}\right)$

Onde:

$D G P_{\mathrm{dvE}}$ é o $D G P$ levantado para a direção de visão "Esquerda";

$D G P_{\mathrm{dvC}}$ é o $D G P$ levantado para a direção de visão "Central";

$D G P_{\mathrm{dvD}}$ é o $D G P$ levantado para a direção de visão "Direita";

$\% \mathrm{t}_{\mathrm{dvE}}$ é a percentagem de tempo olhando para a direção de visão "Esquerda";

$\% \mathrm{t}_{\mathrm{dvC}}$ é a percentagem de tempo olhando para a direção de visão "Central”; e

$\% \mathrm{t}_{\mathrm{dvD}}$ é a percentagem de tempo olhando para a direção de visão "Direita".

\section{Avaliações subjetivas dos participantes}

Com a finalidade de coletar dados subjetivos dos participantes e identificar as preferências gerais do ambiente de trabalho, foram aplicados questionários avaliativos. O questionário (Figura 3) foi baseado em três modelos utilizados em estudos de conforto visual (SAXENA et al., 2013; VAN DEN WYMELENBERG; INANICI; JOHNSON, 2010), contendo modificações de acordo com as necessidades de obtenção de dados desta pesquisa. As perguntas 1 a 5 questionavam os participantes sobre aspectos relacionados a ambientes de trabalho de uma maneira geral, onde foi avaliada a preferência pela presença/operação de janelas e cortinas. As questões seguintes eram relacionadas ao ambiente do experimento. Na pergunta 6 foi solicitado aos participantes classificar a sensação de ofuscamento, no momento da realização de cada uma das tarefas, em uma das seguintes categorias: imperceptível, notado (tolerável por um dia), perturbador (tolerável de 15 a 30 minutos) ou intolerável. 
Figura 3 - Questionário usado para levantamento das avaliações subjetivas dos participantes QUESTIONÁRIO AVALIATIVO USUÁRIO E AMBIENTE

1. Para você considerar um local de trabalho agradável ele deve: (marque de 1 a 3 , sendo 1 mais importante)
( ) Estar livre de ofuscamento (brilhos excessivos)
( ) Estar livre de sombras
( ) Apresentar nível de iluminação suficiente para realizar a tarefa
( ) Apresentar janelas

2. O quanto é importante para você ter uma janela no seu trabalho? (marque com um $X$ somente uma das respostas)

( ) Muito importante ( ) Moderadamente importante ( ) Não é importante

3. Marque as 3 opções mais importantes para você, sobre as vantagens de ter uma janela no ambiente de trabalho. (marque de 1 a 3, sendo 1 mais importante)
( ) Permite saber a hora do dia
( ) Permite o calor entrar
( ) Deixa você ver o que está acontecendo lá fora
( ) Permite ventilação natural
( ) Faz a sala parecer mais espaçosa
( ) Possibilita entrada de luz

( ) Possibilita descansar a visão

4. Marque as 3 opções mais importantes para você, sobre as desvantagens de ter uma janela no ambiente de trabalho. (marque de 1 a 3, sendo 1 mais importante)
( ) Deixa entrar muito calor no verão
( ) Causa ofuscamento (brilhos excessivos)
( ) Deixa entrar muito ar frio no inverno
( ) Permite muita luz do sol

5. Por que você fecharia as cortinas neste ambiente de trabalho?
( ) Muita luz
( ) Aumentar a concentração na atividade
( ) Privacidade
( ) Não fecharia

6. Classifique o ofuscamento (brilhos excesivos) percebido no momento da realização das tarefas desta pesquisa:

\begin{tabular}{|l|l|l|l|l|}
\hline \multicolumn{1}{|c|}{ Tarefas } & Imperceptível & $\begin{array}{c}\text { Notado } \\
\text { (tolerável por 1 dia) }\end{array}$ & $\begin{array}{c}\text { Perturbador (tolerável } \\
\text { por 15,30 minutos) }\end{array}$ & Intolerável \\
\hline Leitura no monitor & & & & \\
\hline Leitura e escrita no papel & & & & \\
\hline Digitando & & & & \\
\hline Ao telefone & & & & \\
\hline
\end{tabular}

7. Responda às questões abaixo de acordo com o nível de concordância sobre a afirmação:

\begin{tabular}{|l|l|l|l|l|l|}
\hline \multicolumn{1}{|c|}{ Afirmações } & $\begin{array}{c}\text { Discordo } \\
\text { Totalmente }\end{array}$ & Discordo & Neutro & Concordo & $\begin{array}{c}\text { Concordo } \\
\text { Totalmente }\end{array}$ \\
\hline $\begin{array}{l}\text { Estou satisfeito como a aparência visual } \\
\text { deste escritório }\end{array}$ & & & & & \\
\hline $\begin{array}{l}\text { Estou satisfeito com o brilho refletido das } \\
\text { paredes e janelas }\end{array}$ & & & & & \\
\hline $\begin{array}{l}\text { Estou satisfeito com a quantidade de luz para } \\
\text { trabalhar no computador }\end{array}$ & & & & & \\
\hline $\begin{array}{l}\text { Estou satisfeito com a quantidade de luz para } \\
\text { ler e escrever no papel }\end{array}$ & & & & & \\
\hline $\begin{array}{l}\text { A tela do computador é legível e não possui } \\
\text { reflexos }\end{array}$ & & & & & \\
\hline A luz está bem distribuída & & & & & \\
\hline
\end{tabular}

Por fim, a pergunta 7 mediu, através de uma escala likert de cinco pontos, o nível de concordância com relação às seguintes afirmações: "Estou satisfeito como a aparência visual deste escritório", "Estou satisfeito com o brilho refletido das paredes e janelas", "Estou satisfeito com a quantidade de luz para trabalhar no computador", "Estou satisfeito com a quantidade de luz para ler e escrever no papel", "A tela do computador 
é legível e não possui reflexos" e "A luz está bem distribuída". As avaliações subjetivas foram levantadas através de questionários aplicados após os monitoramentos.

\section{Resultados e discussões}

Buscando entender o impacto que teria o tempo de visualização e as trajetórias do olhar no cálculo do ofuscamento, foi realizada a ponderação dessas variáveis subjetivas pelos valores de $D G P$. As análises realizadas incluíram: a identificação das áreas e superfícies de interesse visual dos participantes durante a realização das atividades, a descrição das características luminosas dos campos visuais, a caracterização das luminâncias das superfícies de interesse, o cálculo da probabilidade de ofuscamento e ponderação do índice DGP pelo tempo de visualização e, por último, a correlação das avaliações subjetivascom os valores de DGP. Os dados do mapeamento da trajetória do olhar, das luminâncias no campo visual dos participantes e as avaliações subjetivas foram analisados conforme as posições dos participantes no ambiente e as direções dominantes da visão. Análises das relações entre as variáveis de estudo foram realizadas a fim de verificar a associação com o comportamento dos participantes.

Três participantes foram excluídos de algumas análises devido a problemas relacionados ao arquivamento dos dados. Com exceção da P02, todas as posições possuíram no mínimo seis participantes.

\section{Áreas e superfícies de interesse visual}

O monitoramento das atividades com os óculos eye-tracker durou em média 14 minutos para cada participante. As atividades visuais dos participantes foram marcadas por fixações nos planos mais comuns das tarefas: o monitor, o papel e o teclado foram as superfícies mais visualizadas e de maior fixação da visão (Figura 4). Porém, além dessas surperfícies, os participantes buscaram outros pontos do campo visual para fixar a visão. Os participantes da P01 foram os que mais se apropriaram de toda a cena, e os que mais visualizaram as janelas, devido à localização dessa posição com relação às aberturas.

Na Figura 5 é apresentado um exemplo da análise realizada para calcular o tempo de fixação da visão em cada superfície do campo visual. Nessa análise não foi especificada a porção da superfície na qual a visão dos participantes permaneceu focada e sim o tempo em que a visão permaneceu em alguma parte da superfície. O tempo apresentado é a somatória da visualização dos seis participantes localizados na posição P02.

Os participantes na posição P02 e P04 foram os que mais fixaram o olhar para o monitor (43\% do tempo). $\mathrm{Na}$ P02 a relação dos participantes com o restante do ambiente esteve limitada pela proximidade com a parede, além de ter a menor interação com a janela $(0,6 \%)$ (Figura 6). No momento da primeira pausa, após a "leitura no monitor", possivelmente em função da exigência de desligar o monitor, a visão tornou-se mais dispersa. Na segunda pausa, após a leitura do texto no papel, a maioria dos participantes preferiu continuar visualizando o plano do papel. No geral, a maior dispersão da visão aconteceu ao falar ao telefone, devido ao fato de não existir uma superfície específica para realizar a atividade. Durante esse período as janelas e o plano de fundo foram as superfícies mais procuradas pelos participantes. Os participantes da P03 foram os que mais olharam para o papel e para a CPU, e os que menos se interessaram pela visualização do plano de fundo. Ao falar ao telefone, dois participantes dessa posição preferiram olhar para a janela 02 localizada na região periférica do campo visual.

\section{Figura 4 - Mapas de foco das posições. Destaque para as regiões mais visualizadas em vermelho}
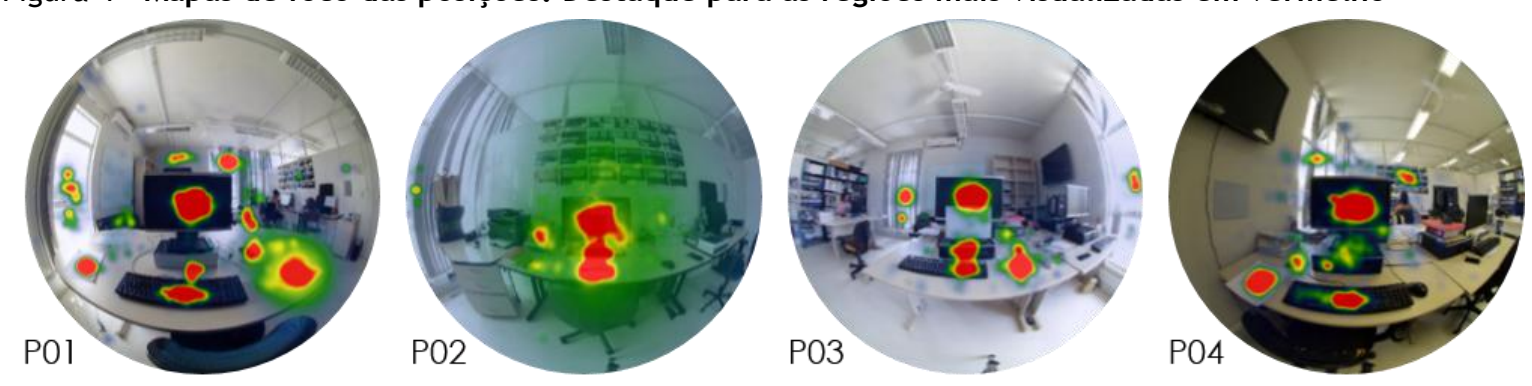

Tempo fixação [ms]

200

2000 
Figura 5 - Exemplo da análise do tempo visualização para cada área de interesse no campo visual dos 6 participantes na posição P02

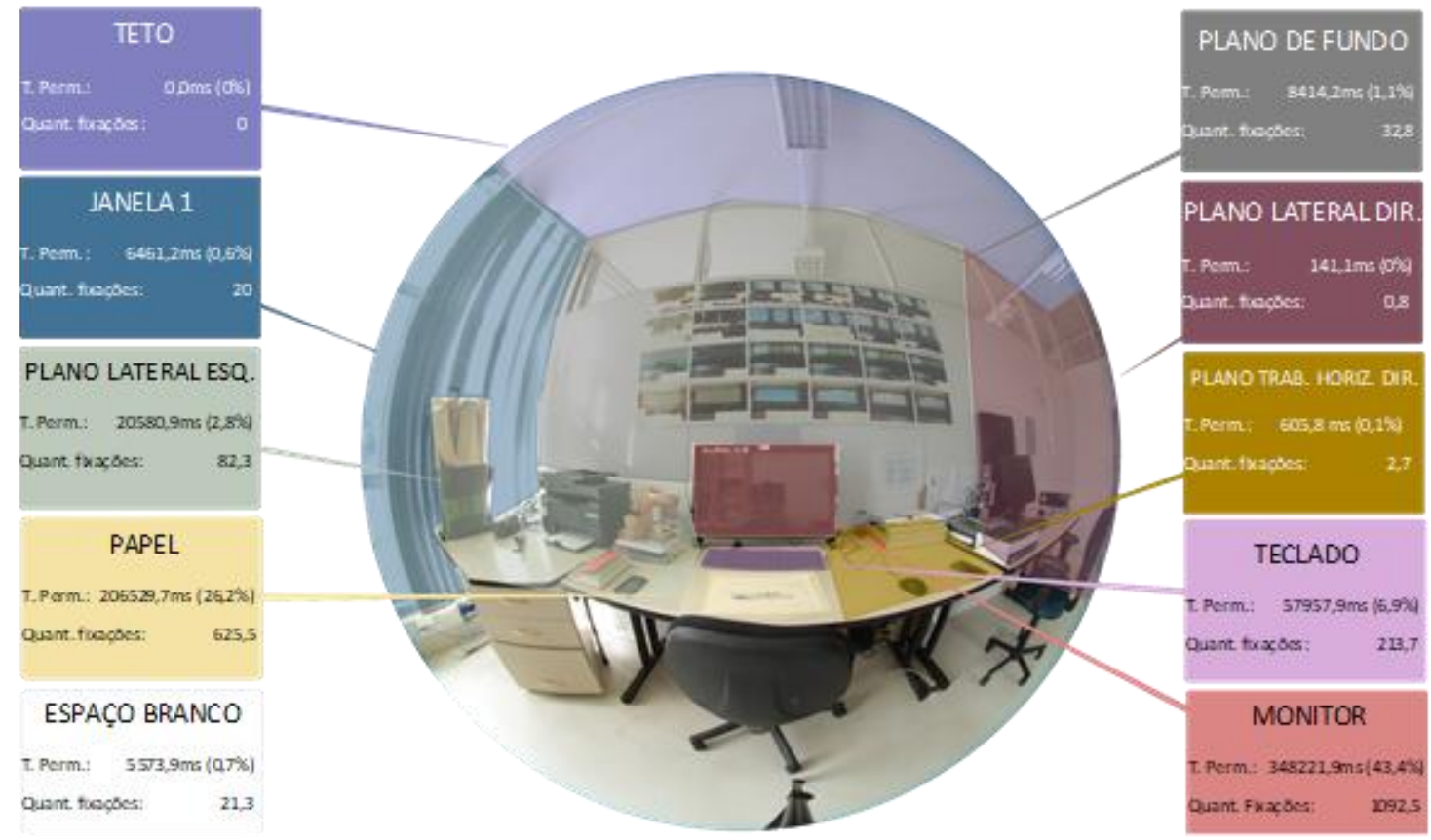

Figura 6 - Porcentagem de visualização para as áreas de interesse do campo visual de cada posição

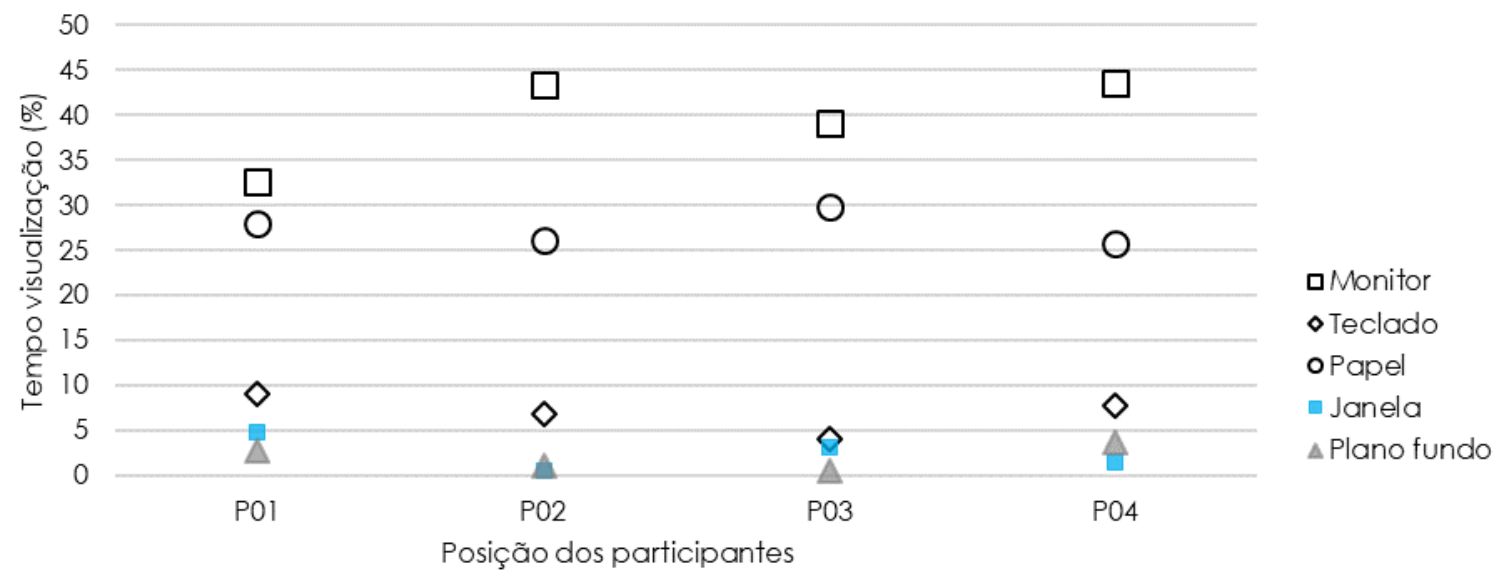

Foi identificado que a direção da visão afeta significativamente o tempo em que a visão permaneceu em cada uma delas $[\mathrm{H}(2)=158.53 ; \mathrm{p}<0.001]$, sendo a direção "central" na qual os participantes fixaram mais o olhar $(\mathrm{Mdn}=70.00 \%)$ (Figura 7). Por outro lado, entre a direção de visão "direita" e "esquerda" não foi encontrada diferença significativa $(\mathrm{U}=4176.00 ; \mathrm{p}=0.88)$. Essas diferenças se devem ao fato de que na direção "central" encontravam-se localizados os objetos das atividades desenvolvidas (computador ou papel).

\section{Características luminosas dos campos visuais}

Na Figura 8 foram plotados os valores das iluminâncias verticais nos olhos (Ev) para cada direção de visão e posição. Os maiores valores de Ev pertenceram aos participantes localizados na P01 ( $\overline{\mathrm{X}}=1153.11$ lux; Mdn= 795.42) e na P02 ( $\bar{X}=1035.00$ lux; Mdn= 455.22). Aqueles participantes localizados na P04 tiveram os menores valores de $\operatorname{Ev}(\bar{X}=329.17$ lux; Mdn= 275.05 lux) enquanto para os participantes do P03 o valor médio da Ev foi igual a 555.53 lux $(\mathrm{Mdn}=316.63 \mathrm{lux})$. Diferenças estatisticamente significativas entre a 
localização dos participantes e os valores de Ev foram encontradas [H $(3)=68.67 ; \mathrm{p}<0.001]$, evidenciando a relação entre a localização das aberturas e os participantes. Diferenças estatisticamente significativas, negativas e fracas foram identificadas entre a posição P01 e P02 (U=1856; $\mathrm{p}=0.003 ; \mathrm{r}=-0.24)$, a P02 e P04 $(\mathrm{U}=1680 ; \mathrm{p}<0.001 ; \mathrm{r}=-0.30)$, a P03 e P04 (U=1504; $\mathrm{p}<0.001 ; \mathrm{r}=-0.26)$. Entre as posições P01 e P03 (U= 864; $<<0,001 ; \mathrm{r}=-0.51)$ e a P01 e P04 $(\mathrm{U}=528 ; \mathrm{p}<0.001 ; \mathrm{r}=-0.69)$ o tamanho do efeito foi moderado. De forma geral, os valores de Ev foram maiores quando os participantes olharam à esquerda ( $\bar{X}=1159.01$ lux; $\mathrm{Mdn}=509.89$ lux) enquanto que poucas variações foram identificadas entre a direção de visão central ( $\overline{\mathrm{X}}=$ 626.54 lux; Mdn= 466.56 lux) e direita ( $\bar{X}=546.80$ lux; Mdn= 405.97 lux $)$, não sendo identificadas diferenças estatisticamente significativas entre as três direções da visão $[\mathrm{H}(2)=1.61 ; \mathrm{p}=0.45]$.

Figura 7 - Diferença do tempo de visualização segundo a direção de visão

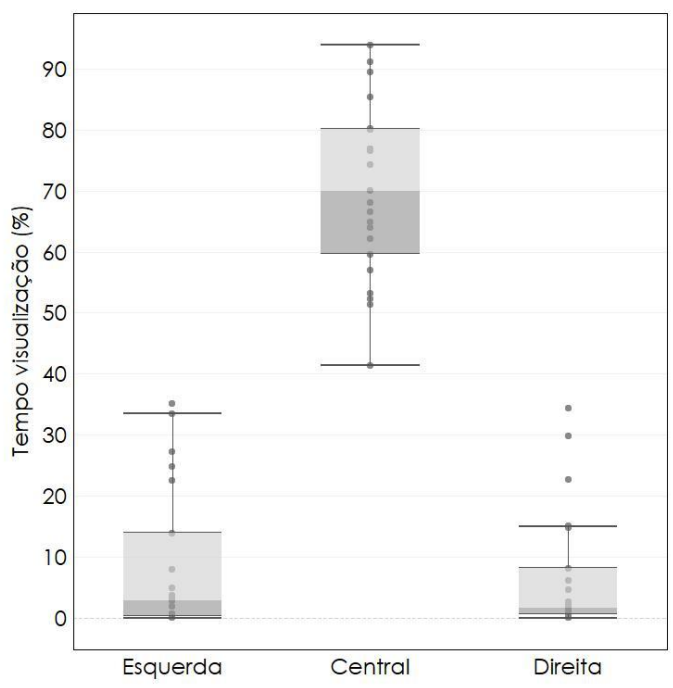

Figura 8 - Diferença na iluminância vertical nos olhos segundo (a) direção da visão, (b) posição e (c) direção da visão por posição
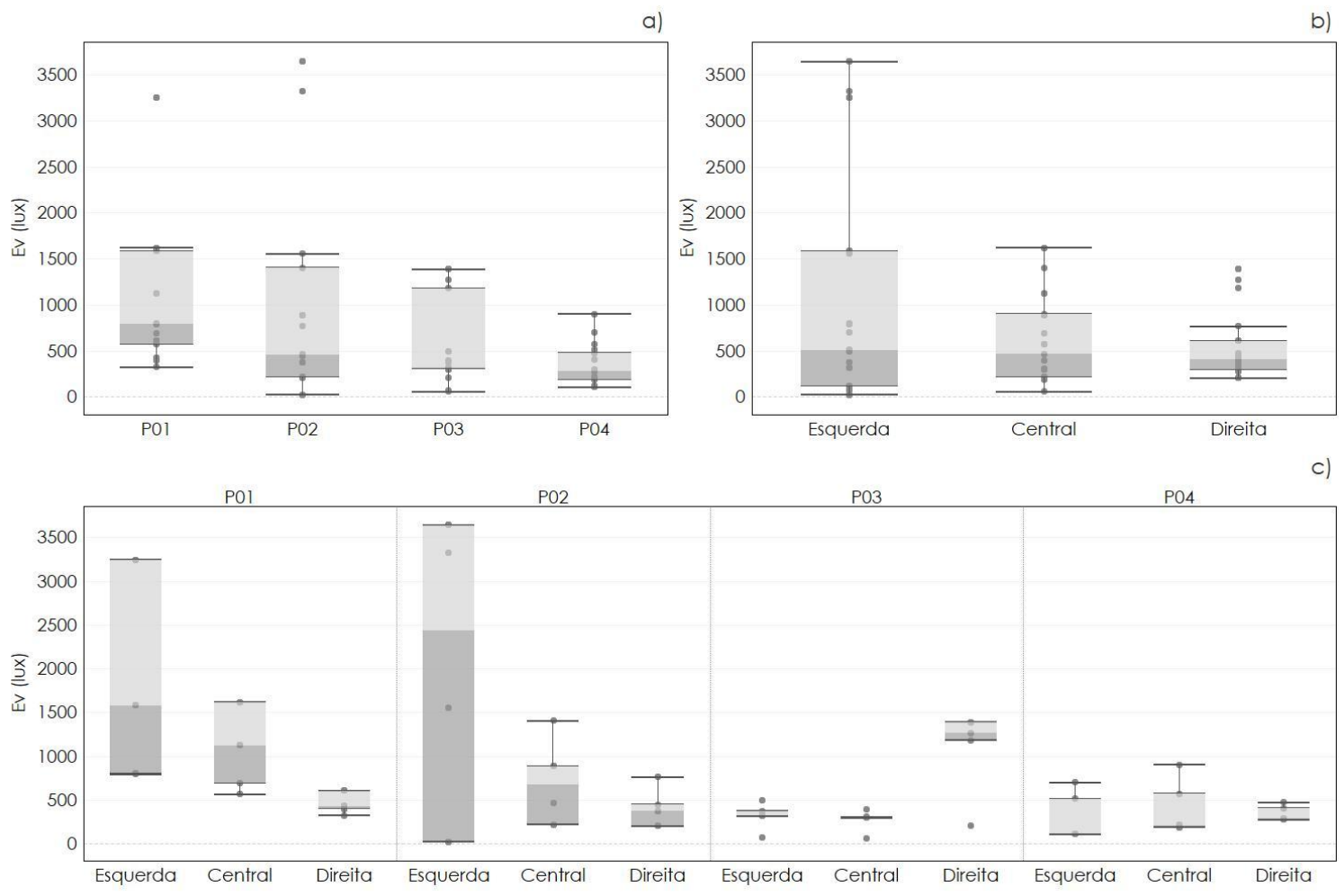
Quando analisadas as variações nos valores de Ev consideranto a posição dos participantes e as variações na direção da visão, os maiores valores foram encontrados para a direção esquerda da P01 ( $\bar{X}=1874 ; M d n=$ 1580 lux) e P02 ( $\bar{X}=2033$ lux; Mdn= 2438 lux). Essa direção esteve caracterizada em ambas as posições por estar mais próxima das aberturas. A P04 esquerda foi a que apresentou os valores medianos mais baixos ( $\bar{X}=275$ lux; Mdn= 113 lux), assim como na P03 central ( $\bar{X}=270$ lux; Mdn= 297 lux $)$.

Com relação à localização dentro do ambiente, os participantes nas posições P01 e P02 tiveram os maiores valores de luminância média no campo visual $\left(\mathrm{L}_{\text {média }}\right)\left(\mathrm{Mdn}=191.36 \mathrm{~cd} / \mathrm{m}^{2}\right.$ e $\mathrm{Mdn}=209.69 \mathrm{~cd} / \mathrm{m}^{2}$, respectivamente), seguidos dos participantes da $\mathrm{P} 03\left(\mathrm{Mdn}=113.60 \mathrm{~cd} / \mathrm{m}^{2}\right)$ (Figura 9). Como esperado, os valores de $\mathrm{L}_{\text {média }}$ no campo visual dos participantes da $\mathrm{P} 04$ foram os mais baixos $\left(\mathrm{Mdn}=90.64 \mathrm{~cd} / \mathrm{m}^{2}\right)$. Essas diferenças indicaram que a posição dentro da sala afetou significativamente as luminâncias médias dos campos visuais $[\mathrm{H}(3)=80.01 ; \mathrm{p}<0.001]$. Diferenças estatisticamente significativas, negativas e moderadas foram identificadas entre a posição P01 e P03 (U=976; $\mathrm{p}<0.001 ; \mathrm{r}=-0,47)$, a P01 e P04 (U=656; $<<0.001$; $r=-0.64)$, a P02 e P03 (U= 1232; p< 0.001; r= -0.37) e a P02 e P04 (U=896; p< 0.001; r= -0.56). Por outro lado, para as condições deste estudo, os valores de $\mathrm{L}_{\text {média }}$ não apresentaram diferenças estatisticamente significativas em relação às três direções de visão avaliadas $[\mathrm{H}(2)=4,62 ; \mathrm{p}=0,10]$.

\section{Luminância das superfícies de interesse}

As maiores luminâncias mapeadas corresponderam às aberturas ou a regiões próximas delas. A reflexão do teto branco e das paredes claras alcançaram valores ao redor de $850 \mathrm{~cd} / \mathrm{m}^{2}$. Porções mais afastadas das aberturas ficaram com valores ao redor de $400 \mathrm{~cd} / \mathrm{m}^{2}$ e os planos comuns de tarefa (monitor, teclado e papel) mantiveram-se com valores entre 50 e $150 \mathrm{~cd} / \mathrm{m}^{2}$. A Figura 10 apresenta a sobreposição da trajetória do olhar sobre os mapas de luminâncias do campo visual do participante 15 na P01, do participante 8 na P02, do participante 4 na P03 e do participante 21 na P04.

Figura 9 - Variação nos valores de $L_{\text {média }}$ do campo visual segundo a direção da visão por posição
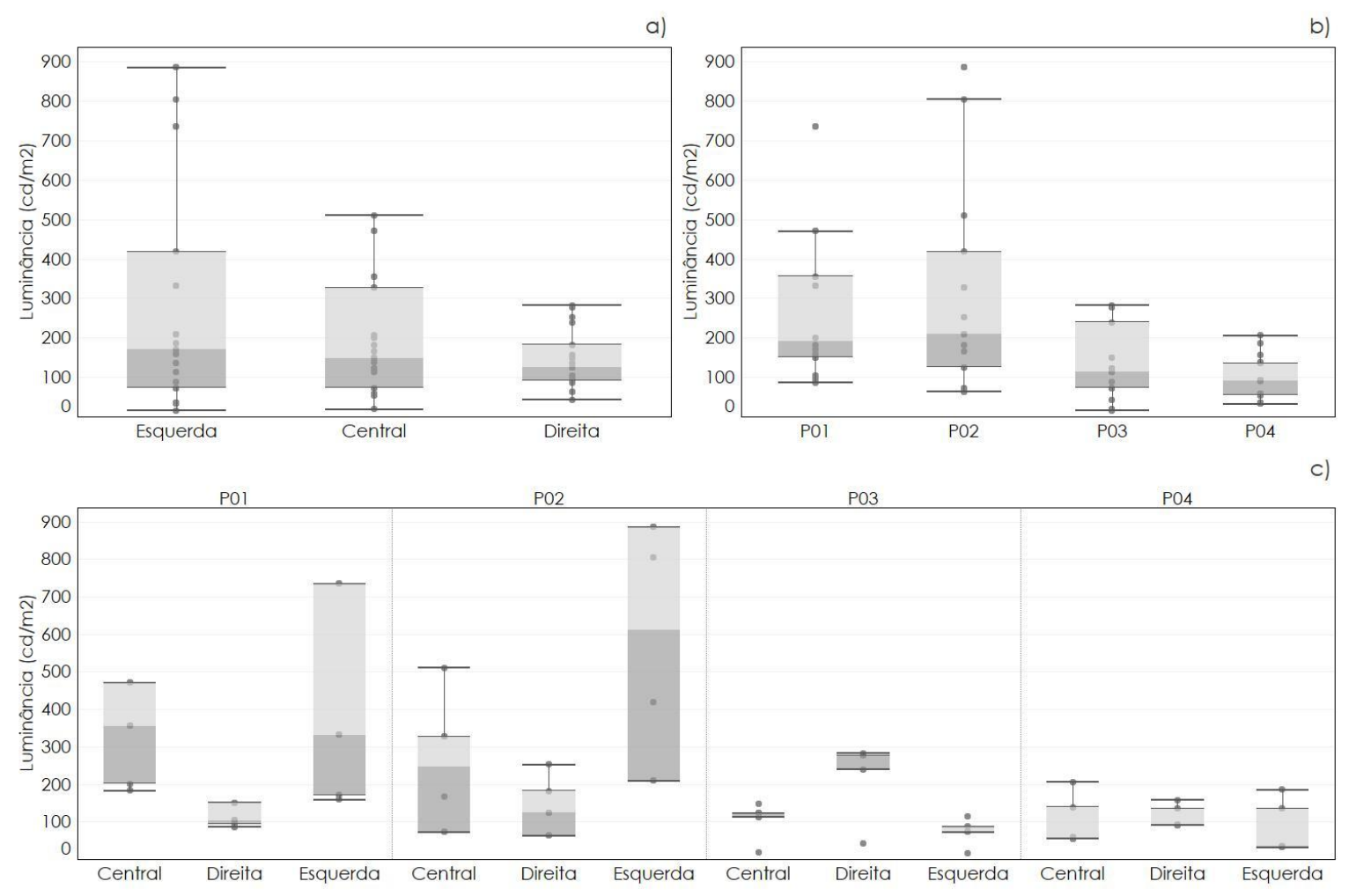
Figura 10 - Trajetória do olhar (preto) sobreposta aos mapas de luminâncias

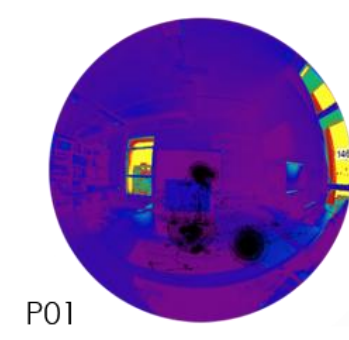

P02

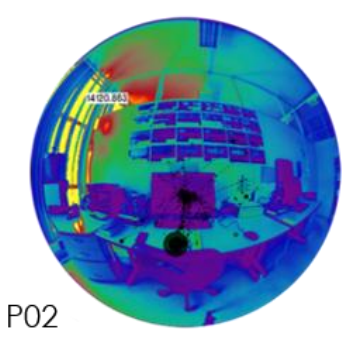

P03

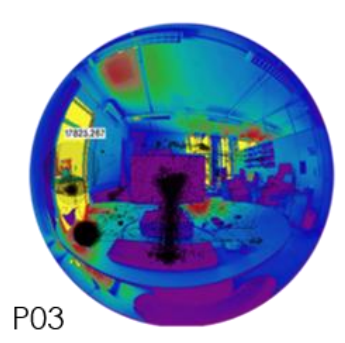

$\mathrm{cd} / \mathrm{m}^{2}$

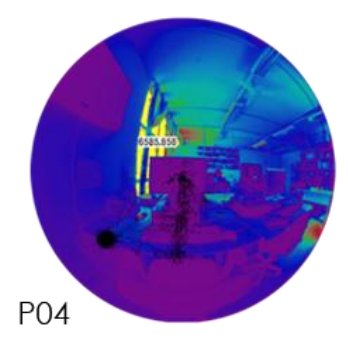

Através da correlação de Spearman foi identificado o relacionamento fraco e estatisticamente significativo, para uma hipótese unilateral, entre a luminância da superfície de interesse e o tempo em que os participantes ficaram olhando para cada uma delas $(\rho=-0.302 ; p<0.01)$ (Figura 11). Para verificar a influência das superfícies de interesse definidas pelas tarefas na relação testada, foi executado o teste de correlação sem considerar as áreas de interesse correspondentes aos planos das tarefas: monitor, mouse, teclado e o papel. Nesse caso, não foi encontrada relação entre a luminância da área de interesse e o tempo $(\rho=-0.054 ; p=$ $0.23)$.

\section{Avaliação do ofuscamento através do DGP}

A Figura 12 permite visualizar a variação dos valores do DGP de uma mesma posição e para as diferentes direções. Os valores de DGP medidos variaram entre "Imperceptível" (89,58\%), "Perceptível" (6,25\%) e "Perturbador" (4,16\%), não sendo registrada nenhuma situação "Intolerável". Apesar de pouca variação nos valores de $D G P$, entre as posições, foram identificadas diferenças estatisticamente significativas entre a localização dos participantes e os valores de $D G P[H(3)=82.28 ; p<0,001]$. Diferenças estatisticamente significativas, negativas e fracas foram identificadas entre a posição P01 e P02 $(U=1456$; p < 0,001; r= 0.37), a P01 e P03 ( $U=1344 ; \mathrm{p}<0.001 ; \mathrm{r}=-0.32)$ e a P02 e P04 $(U=1536 ; \mathrm{p}<0,001 ; \mathrm{r}=-0.35)$. Entre as posições P03 e P04 $(U=1088 ; \mathrm{p}<0.001 ; \mathrm{r}=-0.42)$ e P01 e P04 $(U=304 ; \mathrm{p}<0,001 ; \mathrm{r}=-0.76)$ o tamanho do efeito foi moderado. Como esperado, a direção da visão afetou significativamente os valores de $D G P$ dos participantes $[H(3)=21.41 ; p<0.001]$. Quando a visão esteve dirigida para esquerda os valores de $D G P$ foram maiores do que nas outras duas direções da visão, sendo o valor médio igual a 0.24 correspondente a uma sensação "Imperceptível”. Essa direção contemplava uma das aberturas em todas as posições.

\section{Impacto do tempo de visualização no DGP}

Para cada participante foi ponderado o valor do DGP pelo tempo em que a visão esteve dirigida para cada direção $\left(D G P_{p}\right)$ (Figura 13a). O $D G P$ das direções de visão "Direita" e "Esquerda" teve menor influência no $D G P$ ponderado, fato ocorrido em função do menor tempo de permanência da visão dos participantes para essas direções. Por outro lado, como o tempo de visualização foi maior na direção "Central", os valores o $D G P_{p}$ e o $D G P_{\mathrm{dvC}}$ se aproximaram. Os valores do $D G P$ de cada participante e direção foram plotados na Figura 13b. Para todos os participantes, os valores calculados do $D G P_{p}$ indicaram que, se considerado o tempo na avaliação do ofuscamento, a sensação produzida seria "Imperceptível" (até 0,3$)$.

\section{Avaliações subjetivas do ambiente e diferenças com os valores de DGP}

Através do questionário foram obtidos dados de satisfação dos participantes em relação ao ambiente luminoso. O questionário foi aplicado a cada participante depois da realização das atividades.

Segundo os participantes, um local de trabalho é considerado agradável se "apresenta nível de iluminação suficiente para realizar a tarefa" (44\% dos votos) e "apresenta janelas" (36\% dos votos). Ao serem questionados sobre a importância da presença de janelas em ambientes de trabalho, verificou-se que $80 \%$ dos participantes consideraram muito importante e $20 \%$ considerou moderadamente importante. Referente às vantagens atribuídas às janelas, $40 \%$ dos participantes consideraram como principal vantagem o fato de "possibilitar a entrada de luz". Com relação à principal desvantagem das janelas, 60\% dos participantes apontaram o fato de elas poderem "causar ofuscamento". Quando questionados sobre a operação das cortinas, $44 \%$ dos participantes indicaram como principal motivo para fecharem as cortinas o excesso de luz, 
sendo a maioria dos votos $(63,3 \%)$ dos participantes localizada na P03 e P04. Apenas $8 \%$ dos participantes alegaram que fechariam as cortinas por questões de privacidade. Por outro lado, $44 \%$ dos participantes afirmaram que "não fechariam" as cortinas do ambiente. Esses resultados evidenciam as preocupações dos participantes com os brilhos excessivos e as causas de ofuscamento, as quais podem ter influenciado suas atitudes e comportamentos.

Com relação à avaliação da sensação de ofuscamento durante a realização de cada tarefa, foi identificado que durante a maioria das atividades a sensação do ofuscamento foi considerada "Imperceptível" (80,43\% dos votos) (Figura 14a). Apenas 18,48\% dos votos indicou ofuscamento "Perceptível" durante as atividades e só $1,01 \%$ dos votos indicou uma sensação de ofuscamento "Perturbador", quando realizada a "leitura no monitor" na posição P01. Foi encontrado que a atividade realizada teve um efeito significativo, porém fraco na percepção do brilho $[\chi 2(3)=29,93 ; \mathrm{p}<0,001$; Cramer's V=0,33].

Figura 11 - Porcentagem da frequência de visualização e luminâncias - a cor mostra detalhes sobre as áreas de interesse

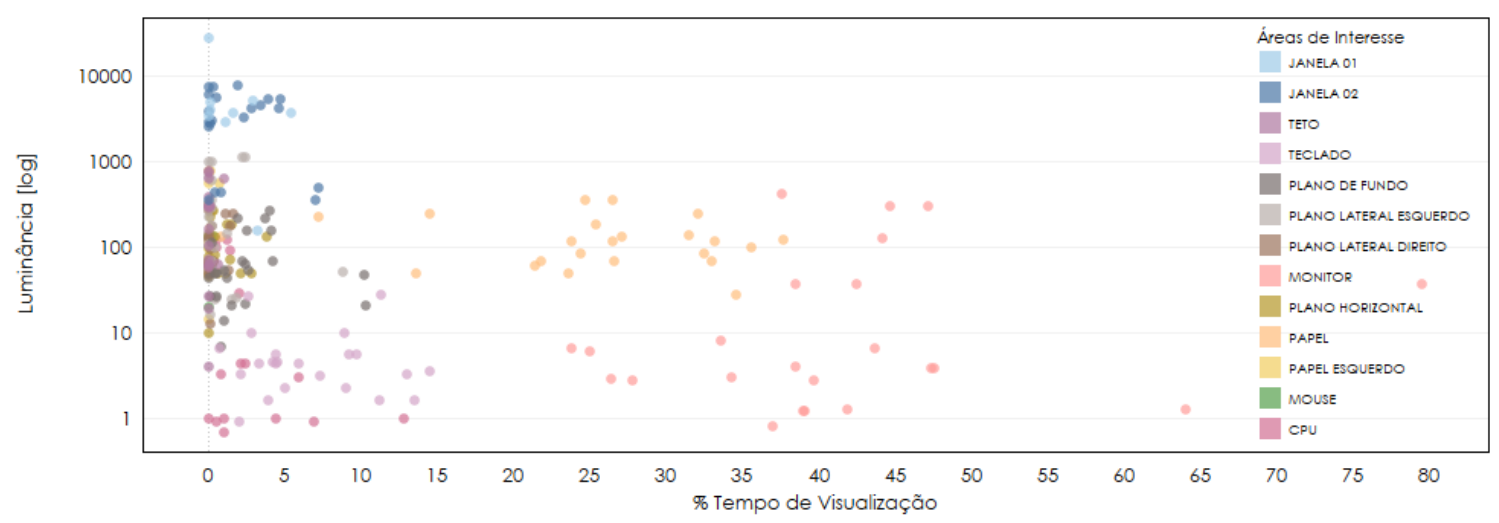

Figura 12 - Dados do DGP segundo (a) direção da visão, (b) posição e (c) direção da visão por posição - a sensação produzida pelo valor de DGP foi plotada por cor
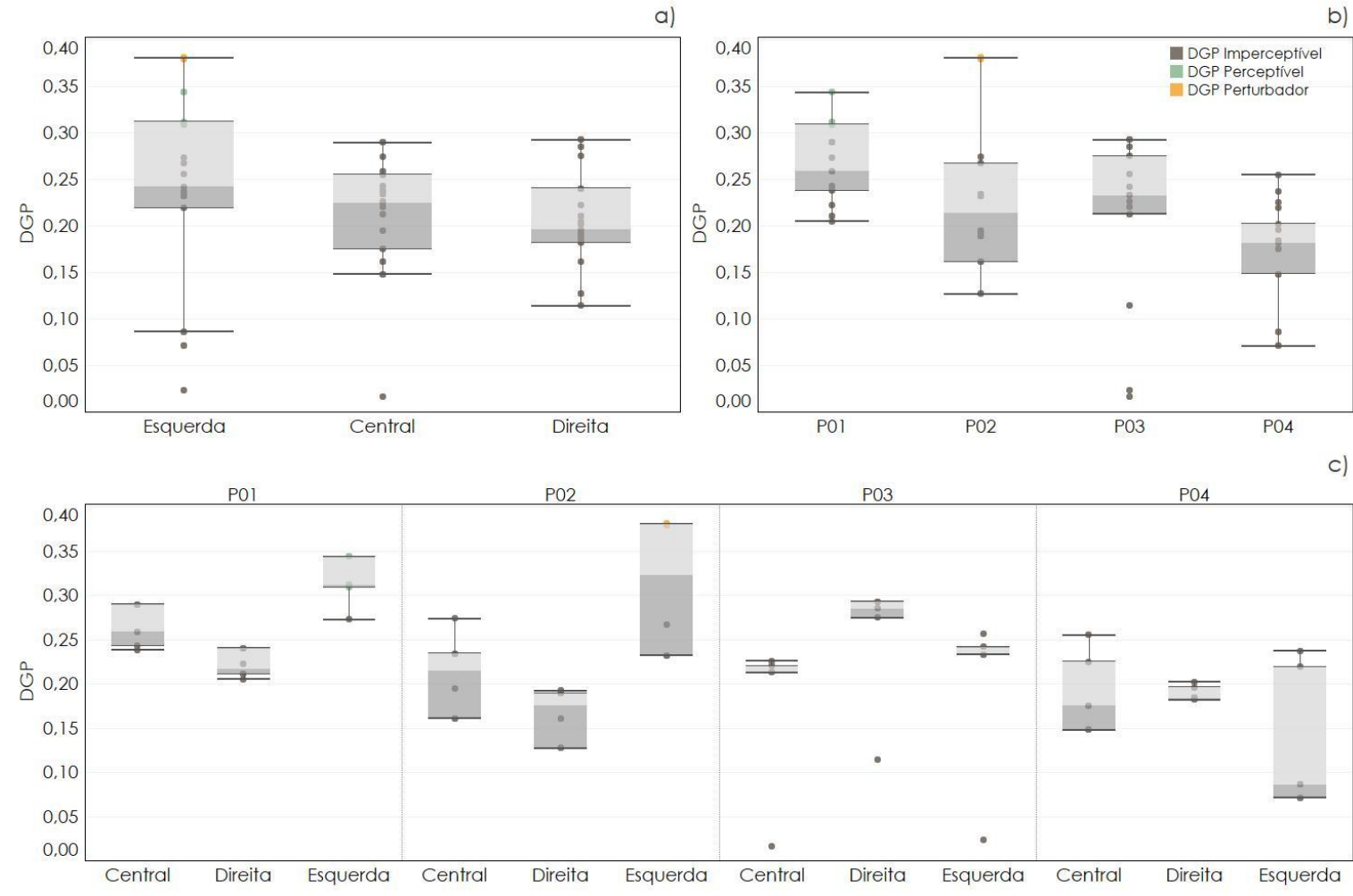
Figura 13 - (a) Diferença percentual entre o DGP de cada direção e valor ponderado pelo tempo de visualização de cada direção e (b) valores de DGP levantados em cada direção (cores) e o valor de $D G P_{p}$ (círculo preto)
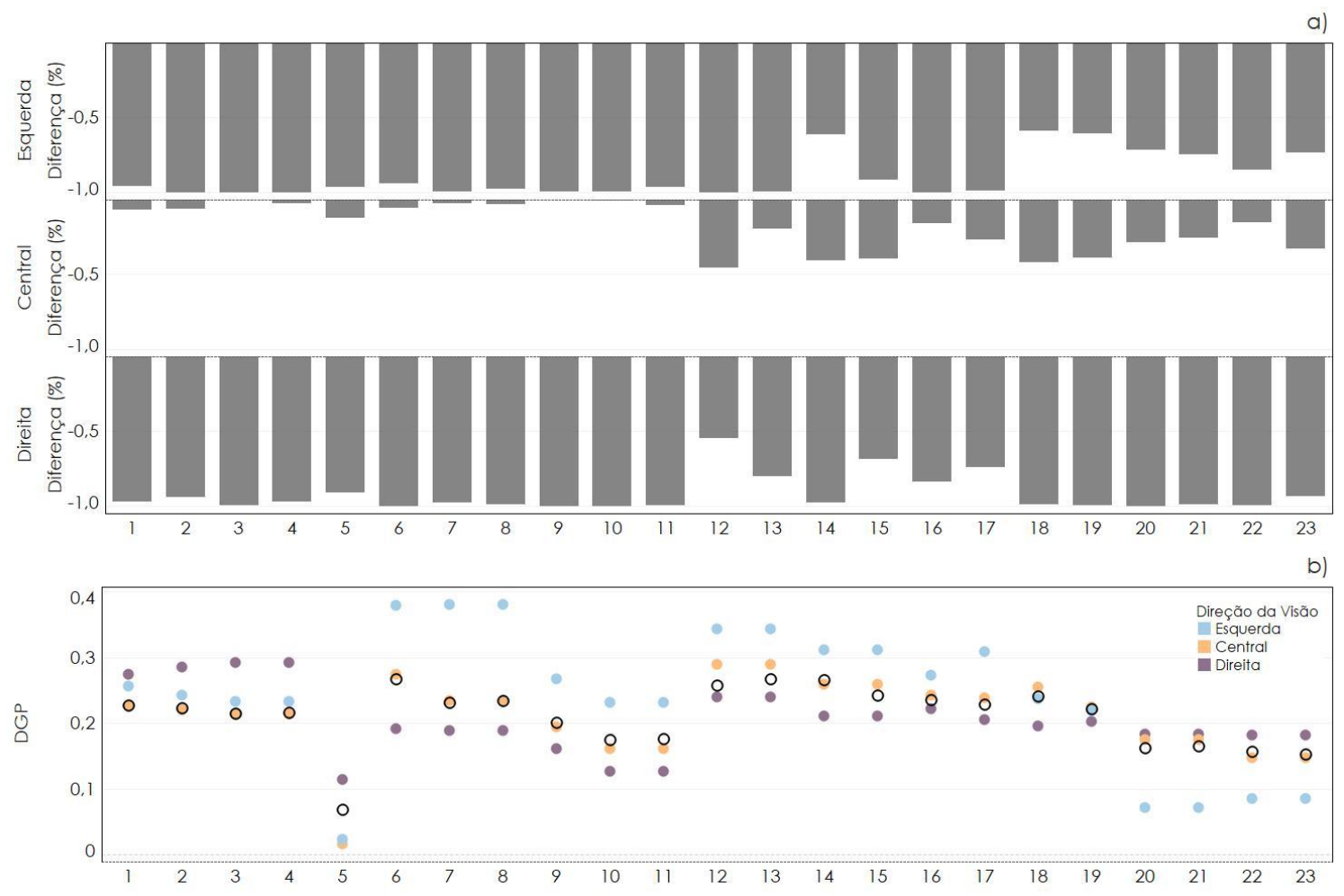

Os votos de nível de satisfação em relação às afirmações realizadas sobre o ambiente são apresentados na Figura 14b. Excetuando a afirmação referente à adequada distribuição da luz no ambiente, com a qual 36\% dos participantes estiveram em desacordo, a maioria dos votos foi positiva com relação à satisfação com as características do ambiente visual. Em relação à satisfação com a aparência, $48 \%$ dos participantes estiveram de acordo com a afirmação. A maioria dos votos em desacordo com as afirmações apresentadas foi dos participantes nas posições P01 e P02.

Com relação aos valores de $D G P$ nas três categorias de avaliação subjetiva realizada pelos participantes, não foram encontradas diferenças significativas entre as médias dos grupos $[H(2)=5,81 ; p=0,06]$. Quando o DGP medido indicou que a sensação de ofuscamento seria "Imperceptível", $72,46 \%$ dos participantes também considerou o brilho "Imperceptível" (Figura 15a). No entanto, quando o DGP indicou uma sensação de brilho "Perturbadora" os participantes avaliaram a sensação como "Imperceptível" (3,62\%) e "Perceptível" $(0,72 \%)$, o que indica que não há relação estatisticamente significativa entre as variáveis $\left[\chi^{2}\right.$ (4) $=7,69 ; p=0,09]$. Foram identificadas diferenças estatisticamente significativas entre o grau de satisfação manifestado no questionário e o valor de $D G P$ das cenas $[H(3)=12,62 ; p=0,006]$. A aparência visual teve maior aceitação dos participantes quando os valores de $D G P$ foram maiores $\left(D G P_{\text {médio }}=0,22 ; D G P_{\text {Mdn }}=0,23\right.$ para "Concordo" e $D G P_{\text {médio }}=0,21 ; D G P_{\mathrm{Mdn}}=0,22$ para "Concordo totalmente") (Figura 15b). Consequentemente, a aceitação visual do ambiente foi maior quando os valores de Ev foram também maiores $\left(E v_{\text {média }}=1042,64\right.$ lux; $E v_{M d n}=606,30$ lux para "Concordo"; $E v_{\text {Média }}=146,47$ lux; $E v_{M d n}=202,78$ lux para "Discordo") (Figura 15c), havendo diferenças estatisticamente significativas entre os graus de aceitação $[\mathrm{H}(3)=46,45 ; \mathrm{p}<0,001]$. 
Figura 14 - (a) Votos da sensação de ofuscamento por posição e tarefa e (b) votos de concordância para afirmações

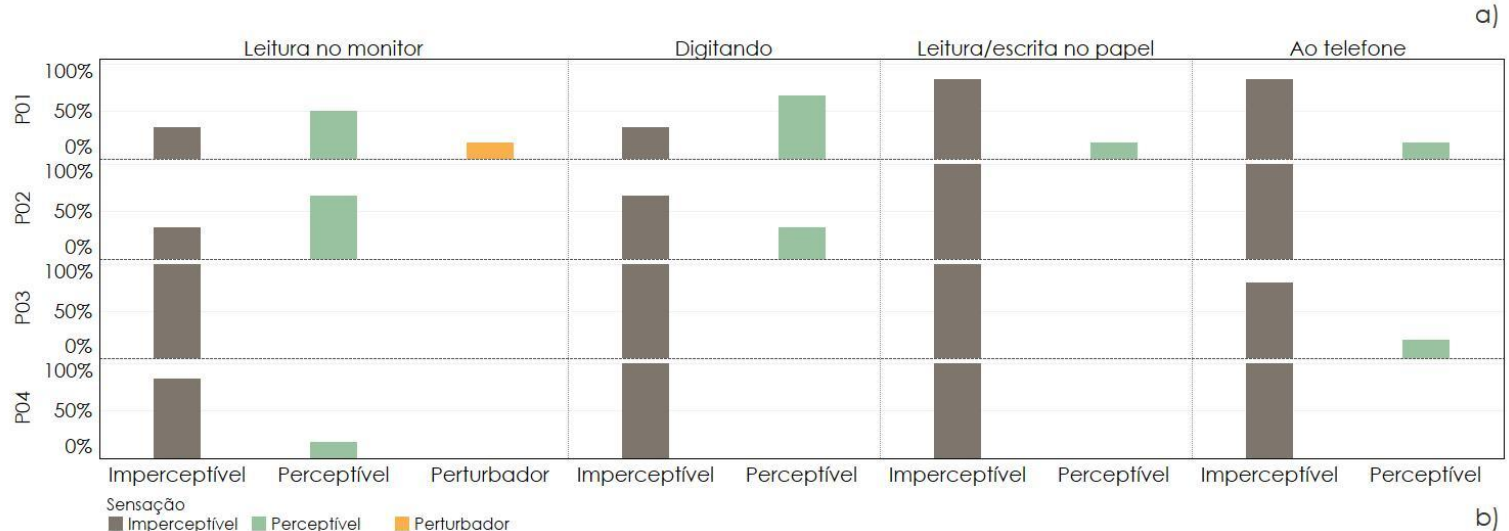

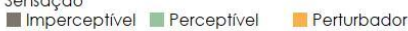

Afirmações / Respostas

$\begin{array}{lcll}\text { O brilho refletido das } & \text { A tela do computador é A quantidade de luz para } & \text { A quantidade de luz para } \\ \text { paredes e janelas é } & \text { trabalhar no computador é ler e escrever no papel é } & \text { A luz está bem distribuída A aparência visual é } \\ \text { satisfatória }\end{array}$ satisfatório

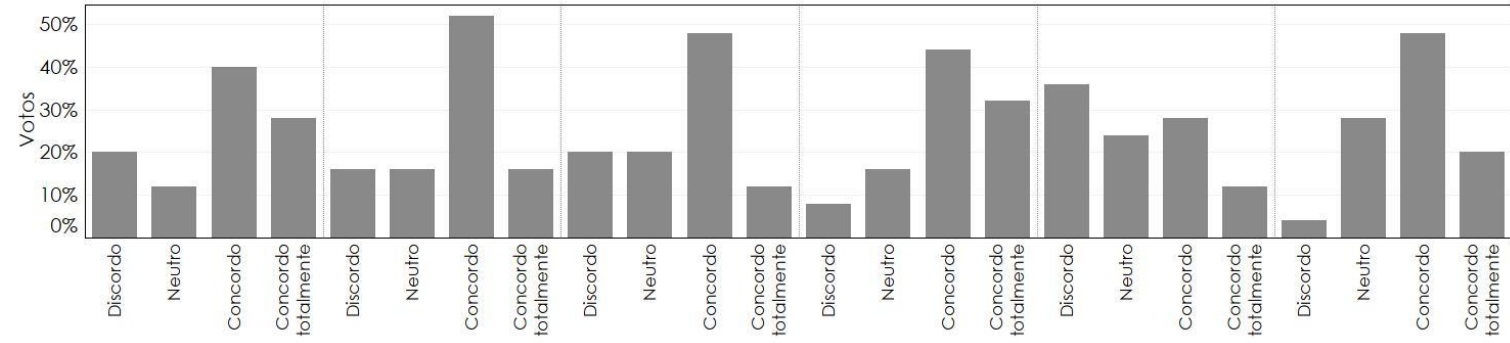

Figura 15 - (a) DGP medido e porcentagem de votos para a sensação de ofuscamento; (b) DGP e satisfação com a aparência visual do ambiente e (c) iluminância vertical nos olhos e satisfação com a aparência visual do ambiente
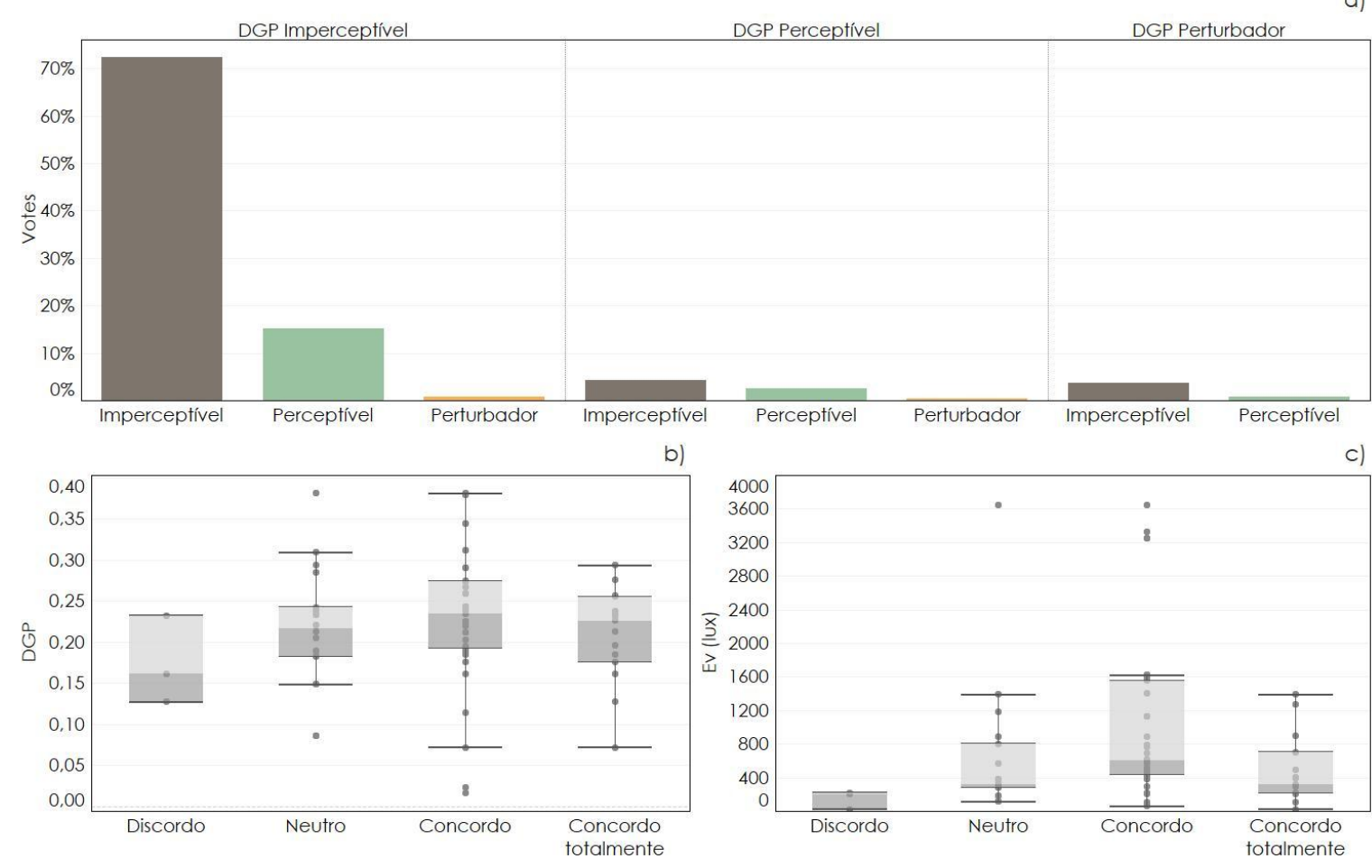


\section{Conclusão}

Embora o processo visual seja dinâmico, os resultados encontrados auxiliam na elaboração de padrões visuais em ambientes de escritórios. Diversos fatores podem influenciar a decisão de permanência da visão para determinada direção como, por exemplo, a atividade desenvolvida, os atrativos no ambiente e o acesso a vista externa, atitudes que podem ser conscientes e inconscientes por parte do usuário. Este artigo buscou analisar a influência da direção da visão e o impacto do tempo de visualização no cálculo da probabilidade de ofuscamento.

Os resultados desta pesquisa confirmaram que, nos intervalos das atividades, as pessoas direcionaram a visão à janela e que a tarefa executada foi a principal variável definidora da direção do olhar, conforme estudos prévios (SAREY KHANIE et al., 2016). De maneira geral, o monitor e o papel foram os elementos mais visualizados pelos participantes, sendo ambos objetos do plano de trabalho. As janelas e os planos de fundo das tarefas, apesar de serem visualizados com menor frequência, foram os elementos mais procurados no campo da visão dos participantes ao realizarem momentos de pausa, reflexão ou ao falar ao telefone. Nesses momentos, verificou-se que a tolerância dos participantes com relação aos brilhos ou contraste excessivos se ampliava. O descanso e os atrativos que a vista externa proporciona foram provavelmente responsáveis pela busca dos participantes por essas vistas, mesmo com níveis elevados de luminância. Porém, a procura por uma paisagem através das aberturas foi reduzida quando foi necessário um deslocamento maior do corpo ou da cabeça. A maioria dos votos para as afirmações foi concordando com a aparência visual do ambiente, mesmo quando os valores medidos de $D G P$ foram elevados. Isso pode ser uma indicação de que as pessoas toleram situações de brilho mais desconfortáveis do que as preditas pelo índice, como apontado por outros autores.

A partir dos resultados foi identificado que a direção da visão afetou o tempo de permanência desta sobre uma superfície, enquanto a posição do participante afetou as médias das luminâncias dos campos visuais. Como era esperado, ambas as variáveis afetaram o $D G P$ das cenas. A ponderação do tempo de visualização pelo valor de $D G P$ indicou uma redução de até $100 \%$ do $D G P_{\text {ponderado }}$ para o $D G P_{\text {estático. Com essa }}$ abordagem, os valores de $D G P_{\text {ponderado }}$ estiveram mais próximos dos votos de satisfação manifestados pelos participantes, ressaltando a importância de considerar as direções de visão e o tempo de visualização em estudos de conforto visual. Dessa forma, conclui-se que o tempo de visualização para determinada direção foi a grandeza que mais influenciou na sensação de ofuscamento, estando diretamente ligado ao tipo de tarefa executada.

A metodologia empregada neste estudo foi complexa e envolveu diversas ferramentas e técnicas para o levantamento das informações, fazendo necessária a coleta por etapas para que os dados obtidos fossem confiáveis. Apesar da riqueza das informações levantadas, o levantamento simultâneo de todos os dados não foi possível devido à complexidade de cada variável estudada. Essa limitação evidencia a dificuldade dos estudos de campo na área de conforto visual. $O$ fato de os experimentos terem acontecido em um ambiente real aproximou os resultados da realidade dinâmica e permitiu a correlação destes com a satisfação dos participantes. A inclusão da tecnologia eye-tracking neste estudo permitiu caracterizar a direção da visão como a mudança da posição dos olhos, da cabeça e do corpo, fazendo com que os dados extraídos da mudança de direção, permanência e visualização fossem mais precisos e confiáveis. O número de participantes, apesar de pequeno, foi suficiente para obter recorrências, possibilitando o cuidado em perceber detalhes das atitudes comportamentais de cada participante. Apesar da determinação da ordem das tarefas a serem executadas ter sido de extrema importância, sentiu-se a necessidade de maior delimitação do tempo de execução para cada uma. Optou-se por não intervir durante a execução das tarefas, sendo que o fato de cada participante levar um determinado tempo para executá-las resultou em possibilidades diferentes de apropriação visual.

Por fim, podem-se ressaltar contribuições para projetos de leiautede ambientes de escritório, adequando a forma como a luz é distribuída no espaço interno. O fato de os participantes preferirem ambientes de trabalho com aberturas aponta para diretrizes projetuais que consideram essa fonte de luz de maneira controlada, como, por exemplo, organizá-las de acordo com a sua função (ver e iluminar), definindo aberturas superiores para a entrada de luz, tendo o teto (superfície menos visualizada) como elemento reflexivo e distribuidor da luz e definindo aberturas na altura dos olhos dos usuários sentados, para que seja possível a visualização da paisagem externa. Ressalta-se também a importância de nos preocuparmos com a iluminação dos planos de tarefas tanto verticais como horizontais, já que a permanência sobre este último foi maior. 


\section{Referências}

ALTOMONTE, S. et al. Visual task difficulty and temporal influences in glare response. Building and Environment, v. 95, p. 209-226, 2016.

CHOI, J.-H.; ZHU, R. Investigation of the potential use of human eye pupil sizes to estimate visual sensations in the workplace environment. Building and Environment, v. 88, p. 73-81, 2015.

GIRALDO VASQUEZ, N. et al. Proposta de um procedimento alternativo para avaliar o ofuscamento: uma abordagem temporal da direção da visão. Ambiente Construído, v. 16, n. 1, p. 143-161, 2016.

HAMEDANI, Z. et al. Visual discomfort and glare assessment in office environments: a review of lightinduced physiological and perceptual responses. Building and Environment, v. 153, p. 267-280, feb. 2019.

HAMEDANI, Z. et al. Lighting for work: a study of the relationships among discomfort glare, physiological responses and visual performance. Building and Environment, v. 167, p. 106478, 2020.

HOWARTH, P. A. et al. Discomfort from glare: the role of pupillary hippus. Lighting Research and Technology , v. 25, n. 1, p. 37-42, mar. 1993.

INANICI, M. Evaluation of high dynamic range photography as a luminance data acquisition system. Lighting Research and Technology, v. 38, n. 2, p. 123-136, 2006.

JAKUBIEC, J. A.; REINHART, C. F. The 'adaptive zone': a concept for assessing discomfort glare throughout daylit spaces. Lighting Research and Technology, v. 44, n. 2, p. 149-170, jun. 2012.

MIRI, M.; ASHTARI, E. Aftab Alpha. Stockholm, 2015. Disponível em: www.aftabsoft.net/aftabalpha.php. Acesso em: 15 fev. 2020.

SAREY KHANIE, M. et al. Integration of eye-tracking methods in visual comfort assessments. In: CleanTech for Sustainable Buildings - CISBAT 11, Lausanne, 2011. Proceedings [...] Lausanne, 2011.

SAREY KHANIE, M. et al. Uncovering relationships between view direction patterns. In: LUXEUROPA, Krakow, 2013. Proceedings [...] Krakow, 2013a.

SAREY KHANIE, M. et al. Investigation of gaze patterns in daylit workplaces: using eye-tracking methods to objectify view direction as a function of lighting conditions. In: CIE CENTENARY CONFERENCE "TOWARDS A NEW CENTURY OF LIGHT”, Paris, 2013. Proceedings [...] Paris, 2013b.

SAREY KHANIE, M. et al.A sensitivity analysis on glare detection parameters. In: International Conference of IBPSa - Building Simulation , 14., Hyderabad, 2015. Proceedings [...] Hyderabad, 2015.

SAREY KHANIE, M. et al. Development of a gaze-driven methodology for estimating luminance values in the field of view for discomfort glare assessments. Lighting Research and Technology, v. 49,n. 7, june, 2016.

SAXENA, M. et al. Final project report office daylighting potential Task 3 of the PIER Daylighting Plus Research Program. California, California Energy Comission, 2013.

STONE, P. A model for the explanation of discomfort and pain in the eye caused by light. Lighting Research and Technology, v. 41, n. 2, p. 109-121, 2009.

SWEITZER, G.; SAITO, S. Pupillary response among VDU users in daylighted workplaces. Journal of human ergology, v. 24, n. 1, p. 88-93, 1995.

TUAYCHAROEN, N.; TREGENZA, P. R. Discomfort glare from interesting images. Lighting Research and Technology, v. 37, n. 4, p. 329-341, dez. 2005.

TUAYCHAROEN, N.; TREGENZA, P. R. R. P. View and discomfort glare from windows. Lighting Research and Technology, v. 39, n. 2, p. 185-200, jun. 2007.

VAN DEN WYMELENBERG, K.; INANICI, M.; JOHNSON, P. The effect on luminance distribution patterns on occupant preference in a daylit office environment. Leukos, v. 7, p. 1-18, oct. 2010.

VIEIRA DIAS, M. et al. Toward proper evaluation of light dose in indoor office environment by frontal lux meter. Energy Procedia, v. 122, p. 835-840, 2017.

WIENOLD, J. Dynamic daylight glare evaluation. In: BUILDING SIMULATION, Freiburg, 2009.

Proceedings [...] Freiburg, 2009. 
WIENOLD, J.; CHRISTOFFERSEN, J. Evaluation methods and development of a new glare prediction model for daylight environments with the use of CCD cameras. Energy and Buildings, v. 38, n. 7, p. 743757, jul. 2006.

YACINE, S. M. et al. Towards a new model of light quality assessment based on occupant satisfaction and lighting glare indices. Energy Procedia, v. 122, p. 805-810, 2017.

YAMIN GARRETÓN, J. A. et al. Degree of eye opening: a new discomfort glare indicator. Building and Environment, v. 88, p. 142-150, 2015.

\title{
Agradecimentos
}

Os autores agradecem à Coordenação de Aperfeiçoamento de Pessoal de Nível Superior - Brasil (Capes) Código de Financiamento 001 pelas bolsas de pós-graduação e ao CNPq - Brasil (Bolsa PQ 307179/2016-8) pelo suporte financeiro. Agradecemos também ao Núcleo de Gestão de Design (NGD) da Universidade Federal de Santa Catarina, à Aline Gobbi pelo apoio técnico durante o uso dos óculos eye-tracking, e aos outros envolvidos na pesquisa, especialmente aos voluntários.

\section{Gabriela Silva Goedert}

Pós-Graduação em Engenharia Civil | Universidade Federal de Santa Catarina | Campus Universitário Reitor João David Ferreira Lima, s/n, Trindade | Florianópolis - SC - Brasil | CEP 88040-900 | Tel.: (48) 3721-7687 | E-mail: gabrielasgoedert@gmail.com

\section{Natalia Giraldo Vasquez}

Pós-Graduação em Arquitetura e Urbanismo | Universidade Federal de Santa Catarina | Tel.: (48) 3721-9797 | E-mail: ngiraldv@gmail.com

\section{Fernando Oscar Ruttkay Pereira}

Departamento de Arquitetura e Urbanismo | Universidade Federal de Santa Catarina | E-mail: ruttkay.pereira@ufsc.br

\author{
Ambiente Construído \\ Revista da Associação Nacional de Tecnologia do Ambiente Construído \\ Av. Osvaldo Aranha, $99-3^{\circ}$ andar, Centro \\ Porto Alegre - RS - Brasil \\ CEP $90035-190$ \\ Telefone: +55 (51) 3308-4084 \\ Fax: +55 (51) 3308-4054 \\ www.seer.ufrgs.br/ambienteconstruido \\ E-mail: ambienteconstruido@ufrgs.br
}

